\title{
Development and testing of a lithium ion source and injector
}

\author{
P. A. Seidl, ${ }^{1}$ W. W. Greenway, ${ }^{1}$ D. P. Grote, ${ }^{2}$ J-Y. Jung, ${ }^{1}$ J. W. Kwan, ${ }^{1}$ S. M. Lidia, ${ }^{1}$ P. K. Roy,,${ }^{1}$ J. Takakuwa, ${ }^{1}$ \\ J-L. Vay, ${ }^{1}$ and W. L. Waldron ${ }^{1}$ \\ ${ }^{1}$ Lawrence Berkeley National Laboratory, Berkeley, California 94720, USA \\ ${ }^{2}$ Lawrence Livermore National Laboratory, Livermore, California 94550, USA
}

(Received 30 January 2012; published 11 April 2012)

\begin{abstract}
We report on the development and testing of an intense lithium ion source and injector for an ion induction accelerator designed for warm, dense matter target heating experiments. The source is a $10.9-\mathrm{cm}$ diameter aluminosilicate emitter on a porous tungsten substrate. For an injector voltage pulse of $120 \mathrm{kV}$, pulse duration of 1.0- $\mu \mathrm{s} \mathrm{FWHM}$, and an operating temperature of $1250^{\circ} \mathrm{C}$, the source emits $35 \mathrm{~mA} \mathrm{of} \mathrm{\textrm {Li } ^ { + }}$ ions. The results follow experimental studies with much smaller sources. The key challenges included beam quality, source lifetime, and heat management.
\end{abstract}

DOI: 10.1103/PhysRevSTAB.15.040101

PACS numbers: 41.75.Ak, 07.77.Ka, 29.27.Ac

\section{INTRODUCTION}

Recently, low-energy ion beams are being applied to the field of warm, dense matter physics, that is, the exploration of matter at or near solid density and temperature from $1 \mathrm{eV}$ to several $\mathrm{eV}$. In order to achieve this transient state of matter, the target material, or sample, must be heated faster than the characteristic thermodynamic expansion time of the target, $\approx 1 \mathrm{~ns}$. Ion beams complement laser heating experiments, because ion beams deposit their energy volumetrically in the target material. In particular, low to medium mass ions (ion mass in the approximate range $4<A<23$ ) with ion kinetic energy of $1-20 \mathrm{MeV}$ deposit most of their energy near the peak of $d E / d x$ vs $E$, which is particularly effective for uniform heating [1].

The new neutralized drift compression experiment (NDCX-II) is based on a $\mathrm{Li}^{+}$beam accelerated to 1-3 MeV. The $\approx 0.1 \mathrm{~A}$ beam current at injection $(E \approx 0.1 \mathrm{MeV})$ is accelerated and compressed to a much higher current and focused to an intense millimeter-sized beam radius at the target [2]. The injector and source are designed for $\approx 1 \mathrm{~mA} / \mathrm{cm}^{2}$ space-charge limited extraction from a 10.9-cm diameter emitter. An acceleration electrode follows the main extraction electrode. The potential of the accelerating electrode is used to tune the transverse envelope of the beam within the injector. The injector is designed to create $60 \mathrm{nC}$, or $4 \times 10^{11}$ ions in a $1-\mu$ sec bunch.

\section{ION SOURCE}

Various methods for the production of alkali ions, and specifically lithium have been demonstrated, for example, aluminosilicate, vapor spark sources, and contact ionizers

Published by the American Physical Society under the terms of the Creative Commons Attribution 3.0 License. Further distribution of this work must maintain attribution to the author(s) and the published article's title, journal citation, and DOI. from refractory metals. The choice of aluminosilicate was driven by the need for high intensity and repetition rate, coupled with low emittance and low impurities in a single charge state. Very high lithium current has been demonstrated, for example, with $\mathrm{LiCl}$ dielectric surface flashover sources [3], operating at injector voltage of $500 \mathrm{kV}$ and creating a $\mathrm{Li}^{+}$current density of $120 \mathrm{~A} / \mathrm{cm}^{2}$. However, the charge state impurities were $25 \%-35 \%$, greater than that required for our application.

Very high current has been demonstrated with vapor $\mathrm{Li}^{+}$ sources ionized by high-power lasers [4], generally at low repetition rate.

Contact ionizer sources have shown ion current densities in an acceptable range [5] with very low emittance. The expected lower ionization efficiency for lithium and associated higher neutral emission from these sources are a concern.

The choice of aluminosilicate is based on successes with other alkalis such as $\mathrm{K}^{+}$[6] which have shown good reproducibility, low emittance, and high current from large surface area sources capable of operating at $>1 \mathrm{~Hz}$. Also, there have been demonstrated reliable $\mathrm{Li}^{+}$sources developed as tokamak plasma diagnostics $[7,8]$. The results here follow on that work to much larger area lithium sources, at $\approx 1 \mathrm{~mA} / \mathrm{cm}^{2}$.

\section{Ion source preparation}

Earlier experiments with 6.35 -mm emitters [9] established the sintering temperature, emitter heating and cooling rate, extracted current density, and source lifetime. In preparing the large emitters, we have followed most of the steps as described in Ref. [9], with a few changes.

(i) High-purity chemicals $\left(\mathrm{Al}_{2} \mathrm{CO}_{3}, 99.7 \% ; \mathrm{SiO}_{2}, 99 \%\right.$; ${ }^{7} \mathrm{Li}_{2} \mathrm{CO}_{3}, 99.7 \%$ isotopically pure, $99.9 \%$ chemically pure) are mixed in a stoichiometric ratio $\left({ }^{7} \mathrm{Li}_{2} \mathrm{CO}_{3}: \mathrm{Al}_{2} \mathrm{CO}_{3}\right.$ : $\left.2 \cdot \mathrm{SiO}_{2}\right)$ for $\beta$ eucryptite $\left(\mathrm{LiAlSiO}_{4}\right)$ and heated to $600^{\circ} \mathrm{C}$ for one hour, which liberates $\mathrm{CO}_{2}$. The chemicals are then thoroughly mixed with a mortar and pestle. 
(ii) The mixture is then heated to $1200^{\circ} \mathrm{C}$ for one hour after which the aluminosilicate is chemically stable and may be stored for later use.

(iii) The surface of the substrate must be sufficiently porous for good adhesion of the coating. Additional etching may be required to open cells that were closed as a result of final machining. Prior to coating, the porous tungsten substrate $(20 \%$ porosity) is clean fired at $1500-1550^{\circ} \mathrm{C}$.

(iv) An aqueous paste of the aluminosilicate is prepared and applied to the porous tungsten substrate to a thickness of $\approx 0.5 \mathrm{~mm}$.

(v) The coated emitter is heated to $1400^{\circ} \mathrm{C}$ ( $\left.\pm 5 \mathrm{C}\right)$, the melting temperature, at a rate of $10^{\circ} \mathrm{C} / \mathrm{min}$, and held at that temperature for 5-10 minutes before cooling at $10^{\circ} \mathrm{C} / \mathrm{min}$. This melting stage establishes a bond with the porous tungsten substrate.

An R\&D furnace large enough to accommodate $11-\mathrm{cm}$ diameter $\times 9 \mathrm{~cm}$ high emitter assembly is used for the source preparation. For the final sintering step, a partial pressure of 258 Torr $\left(96 \% \mathrm{Ar}, 4 \% \mathrm{H}_{2}\right)$ is established before the heating cycle. After the heating cycle and when the sample is at room temperature, it is backfilled with $\mathrm{N}_{2}$. The emitter temperature is monitored with a pyrometer.

After numerous experiments with the $6.35-\mathrm{mm}$ diameter emitters, test coatings were made of $25-\mathrm{mm}$ and $75-\mathrm{mm}$ diameter substrates. These showed that the coating procedure scaled reasonably well to the larger size, yielding coated substrates with the aluminosilicate adhered to most of the surface area. However, during the cooling cycle, aluminosilicate spalled from the surface to a much greater extent than for the smaller samples, probably due to a greater role of differential expansion and contraction at larger dimensions. This was a persistent feature for several iterations of heating and cooling rates. Ions were not extracted from these samples due to the lack of an appropriate extraction and emitter heating system.

Compared to potassium aluminosilicate ion sources, we have found that lithium aluminosilicate is easier to coat on the substrate as a wet aqueous paste. While $\mathrm{K}^{+}$sources require a slow, humidity controlled drying process to avoid cracking before sintering, we have found that $\mathrm{Li}^{+}$can be dried relatively quickly without any visible defects in the dried, "green" coating. However, during the cooling phase of the sintering heat cycle, lithium aluminosilicate tends to crack and spall, more than for potassium aluminosilicate. This may be due to a greater influence of differential thermal expansion between the refractory substrate and the lithium aluminosilicate.

Following these tests, three $10.9-\mathrm{cm}$ diameter emitters were prepared. Because of the expected few-week lifetime for the $\mathrm{Li}^{+}$ion sources, three tungsten emitter substrates were procured so that at least one unused, coated emitter would be available whenever an emitter in NDCX-II began to deplete. The finished, sintered surface is nearly flat, with $0.05 \mathrm{~mm}$ (rms) variations in coating thickness due in part to

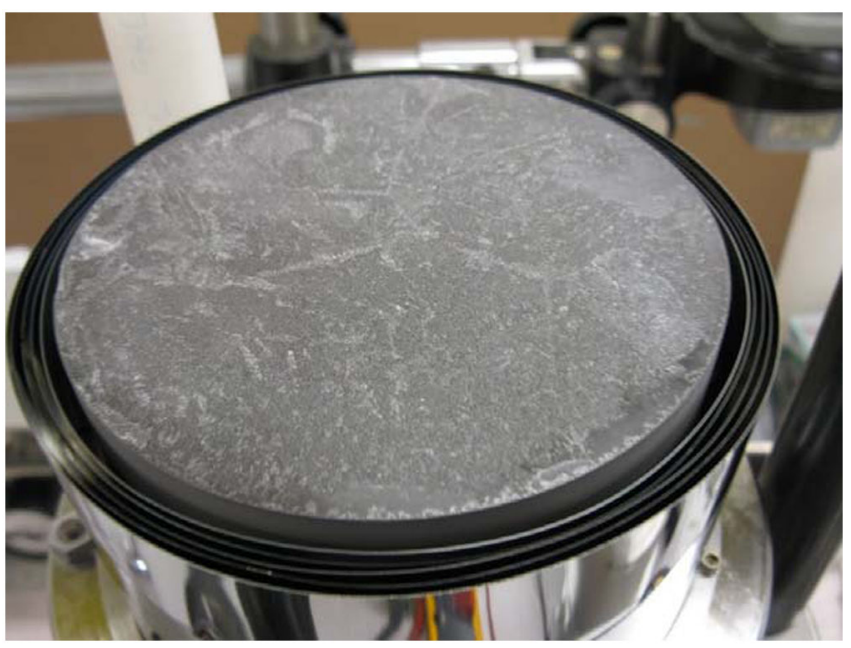

FIG. 1. The emitter, aluminosilicate coated on a porous tungsten substrate, is shown in the heat-shield assembly, prior to ion beam extraction.

the spalling of material mentioned above. Because of the size of the sensor, the smoothness is averaged over a transverse spatial scale of $0.6 \mathrm{~mm}$. A photo of an ion source and its heat-shield assembly is shown in Fig. 1. After sintering the emitter, but before use, the coating is translucent and grey. After use for $>20$ hours at an operating temperature of $1200-1300^{\circ} \mathrm{C}$, the coating loses some of its transparency and is more white and opaque.

\section{INJECTOR AND DIAGNOSTICS}

The NDCX-II injector and source is designed for $\approx$ $1 \mathrm{~mA} / \mathrm{cm}^{2}$ space-charge limited extraction from an 10.9$\mathrm{cm}$ diameter emitter. The emitter is pulsed to an operating voltage of up to $130 \mathrm{kV}$. The extraction electrode is followed by an "accelerating electrode" to enable some control of the envelope during injection of a $0.06 \mu \mathrm{C}$ bunch $\left(4 \times 10^{11}\right.$ ions $)$ in a $1-\mu$ sec FWHM pulse. The accelerating electrode potential also influences the extracted current. The design of the NDCX-II injector is described in Ref. [10]. The high-voltage (HV) pulser is a spark gap switched pulse forming network through a stepup transformer driving a resistor string. The highest voltage output goes to the source. A slightly lower tap point from the resistor chain sends a HV pulse to the extractor electrode, $\approx 117 \mathrm{kV}$ for a source voltage of $130 \mathrm{kV}$. The accelerating aperture potential is established by a DC power supply, $20 \mathrm{kV}$ in the baseline tune for NDCX-II. The $0.45-\mu$ s rise time (5\%-95\%) of the pulser voltage, $\tau$, is nearly matched to the steady-state, space-charge limited transit time of $\mathrm{a} \mathrm{Li}^{+}$ion from the emitter to the exit of the injector for a peak voltage of $120 \mathrm{kV}$ :

$$
\tau \approx 3 \frac{g}{c} \sqrt{\frac{m}{2 V}}=0.45 \mu \mathrm{s}
$$

where $V$ is the gap voltage, $m$ is the ion mass in $\mathrm{eV} / c^{2}, g$ is the anode-cathode gap distance, and $c$ is the speed of light. 


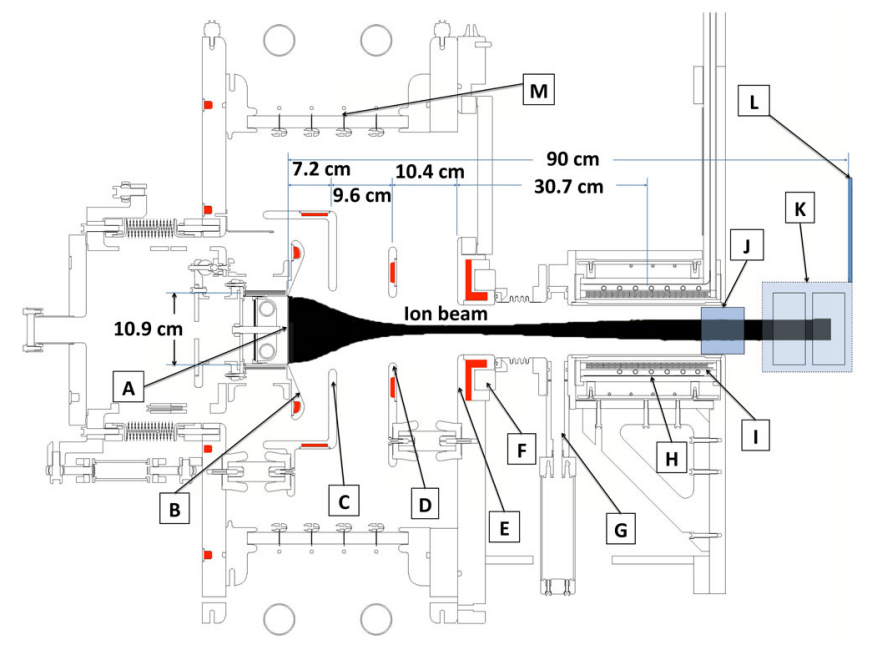

FIG. 2. NDCX-II injector and initial diagnostics. The watercooling channels are shown in red. Legend: A: emitter; B: Pierce electrode; C: extractor aperture (pulsed); D: accelerating aperture; E: ground plate; F: Rogowski coil; G: gate valve; H: corrector coil; I: solenoid; J: electron trap; K: Faraday cup; L: scintillator; M: insulating column.

The maximum repetition rate of the injector system is $0.5 \mathrm{~Hz}$, limited mainly by the current limit of the charging power supply. This is an order of magnitude faster than the anticipated repetition rate of most NDCX-II experiments.

Figure 2 shows the injector and diagnostics setup for the first beam measurements. According to $2 \mathrm{D}$ calculations that include the dielectric constant of the alumina insulator and the geometry of the grading rings, the field along the cylindrically symmetric graded insulating column is calculated to be $<10 \mathrm{kV} / \mathrm{cm}$ over most of the surface of the insulator, for a source voltage of $130 \mathrm{kV}$. These calculations omit the possible charge-up of the insulator which can significantly affect the field.

Based on earlier tests with $6.35 \mathrm{~mm}$ test sources [9], the lifetime of the lithium aluminosilicate source is approximately 40-100 hours when operated between $1200-1275^{\circ} \mathrm{C}$. Since the source will need to be replaced frequently, the emitter assembly is designed so that a freshly coated tungsten substrate can be installed within a few hours, while maintaining good alignment with respect to the Pierce electrode.

\section{A. Ion source heating}

Lithium requires a higher operating temperature than higher-mass alkali sources to achieve $1 \mathrm{~mA} / \mathrm{cm}^{2}$ : about $1250-1275^{\circ} \mathrm{C}$, which presents engineering challenges for heat management and temperature uniformity. That is due to the lower margin between the space-charge limit (set by the injector voltages and geometry) and the emission limit (governed by the ion emissivity of the surface-a strong function of temperature).

The high filament temperature discouraged the choice of a potted filament. Instead, a nearly freestanding design was chosen, which leads to a somewhat higher filament operating temperature (Fig. 3). The emitter is heated with a non-sag tungsten filament to $1920^{\circ} \mathrm{C}$ for an average emitter temperature of $1319^{\circ} \mathrm{C}$. The filament dopants, rhenium, potassium, and aluminum, impede recrystallization, improve creep resistance, and minimize sagging of the filament [11]. The filament, supported within the groove of the tungsten substrate with boron nitride rings, may be removed or replaced independently of the emitter substrate. After initial tests, the number of turns was reduced from 70 to 63 to reduce the risk of turn-to-turn electrical contact on the inner diameter of the toroid.

Through iterative finite-element thermal modeling, a specification of $\Delta T= \pm 5^{\circ} \mathrm{C}$ for an emitter temperature of $T=1275^{\circ} \mathrm{C}$ was met by varying the filament geometry and the housing of the filament within the porous tungsten substrate. The design effort included a steady-state thermal analysis using the program ANSYS [12], to predict the steady-state temperature of the uncoated, 20\%-porous tungsten emitter and heat loss from the source assembly. The solution was constrained by the known material properties of the substrate and the heat shield. Models of temperature-dependent emissivity and conductivity [13] were used for the tungsten, stainless-steel, alumina, copper, molybdenum components, and the filament. The model was axisymmetric, and the filament geometry was approximated by a number of azimuthal tungsten wire hoops with total area equal to the actual toroidal filament shown in Fig. 3. Heat transfer by the water-cooling system was included in the model. The boron nitride rings were not included in the axisymmetric model of heating. This has two consequences for the model: The boron nitride parts will have some conductive heat path for the filament and it shields radiative heating to the substrate.

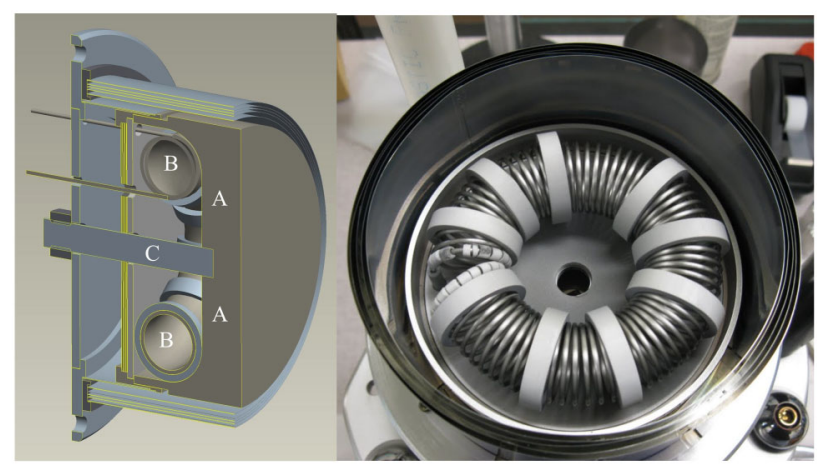

FIG. 3. Left: CAD model of the 10.9-cm diameter emitter, heating filament, and heat shield. The filament is region $\mathrm{B}$, and the central support rod is marked $C$. Right: The filament is shown, before installation in the source. The tungsten filament, $1.52-\mathrm{mm}$ diameter, is electrically isolated from the heat-shield assembly by boron nitride hoops. Smaller boron nitride beads isolate the filament leads where they exit the heat-shield assembly for contact with the leads from the filament power supply. 
Three parameters were empirically adjusted: (i) The thickness of the planar slab between the emitter and the heating coil (region A in Fig. 3, varied from 5 to $25 \mathrm{~mm}$ ) was optimized at $18 \mathrm{~mm}$. (ii) The filament geometry and location in the back of the tungsten substrate was varied. The major and minor diameter of the toroidally wound filament was optimized at 68 and $23 \mathrm{~mm}$, respectively. (iii) The diameter of the center support rod $(C)$, which influences the temperature uniformity across the surface of the emitter, was adjusted.

Nonoptimized results showed a temperature nonuniformity of up to $\pm 15^{\circ} \mathrm{C}$. The competing considerations are the desire to minimize the thermal mass of the tungsten substrate and the need to achieve sufficiently uniform heating at the surface.

All measured temperature values of the emitting surface or porous tungsten reported in this paper are the direct reading from a Leeds \& Northrup model 8632-C disappearing-wire style optical pyrometer, calibrated for an emissivity of $\varepsilon=0.4$, close to that of the porous tungsten substrate $\left(\varepsilon_{W}=0.39\right)$. The emissivity of the hot aluminosilicate is not known precisely, and for thin coatings (semitransparent at room temperature), the effective emissivity may be influenced by the underlying tungsten substrate.

Figure 4 shows the prediction, as well as the measured emitter temperature as a function of filament power. The model prediction agrees with the measured temperature of the bare tungsten emitter to within $20^{\circ} \mathrm{C}$ in the temperature and power range of interest. A power-law best fit to the model yields $T_{s}=k P^{0.22}$, while simple radiative heat loss

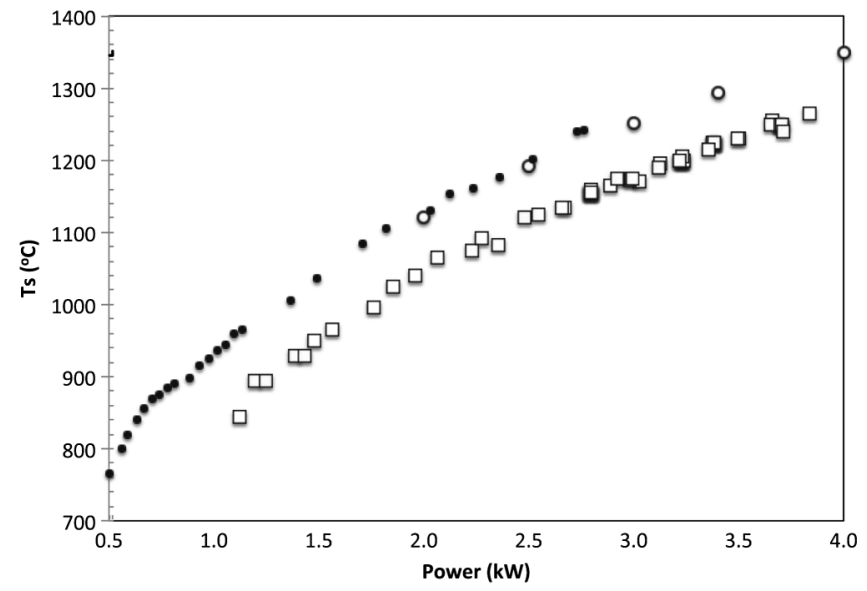

FIG. 4. The modeled and measured lithium ion source surface temperature (vs filament power) for the NDCX-II emitter are compared. The open circles are from the ANSYS steady-state finite-element model of the filament power dissipation in the injector. The solid black line is an empirical power-law fit to the model. The measured temperature of the uncoated substrate (closed circles) is in excellent agreement with the model. The pyrometer indicated temperature of the coated source (squares) is about $75^{\circ} \mathrm{C}$ lower than the temperature of the uncoated source. would be approximately proportional to $P^{1 / 4}$. Meanwhile, the measured temperature of the coated source (squares) is about $75^{\circ} \mathrm{C}$ lower than temperature of the uncoated source. This difference is due to the emissivity of the thin aluminosilicate coating on the substrate. In the future, this discrepancy between the pyrometer reading and the true temperature can be resolved via a thermocouple measurement of the coating.

Since the coating is thin, and is in excellent contact with the tungsten substrate, we assume that the real temperature of the tungsten substrate and the coating are nearly equal and thus the real temperature of the coated emitter is 75 degrees greater than the direct pyrometer reading of temperature. The observed temperature variation across the emitter surface was $<15^{\circ} \mathrm{C}$, in fair agreement with the predicted temperature variation of 9-10 C. The observed temperature gradient was monotonic in the horizontal direction, perhaps due to left-right asymmetries in filament lead placement and the water-cooling inlet and outlet.

\section{B. Diagnostics}

A Rogowski coil is built into the grounded exit aperture of the injector, just upstream of the first solenoid (Fig. 2). The solenoid, designed to match the beam exiting the injector to the desired envelope at the beginning of the accelerator, is pulsed with a half-sine waveform of duration $2.5 \mathrm{msec}$, and a peak operating field of 2.5 Tesla for a peak current of $\approx 6.75 \mathrm{kA}$. For the measurements reported here, the solenoid was not energized.

Using the WARP [14] particle-in-cell computer code, simulations for a wide range of injected beam current showed that there is no expected particle loss as the beam drifts to the diagnostics in the absence of solenoid focusing. The diagnostics include a large Faraday cup with a negatively biased cylindrical electrode upstream of the collector to suppress the secondary $e^{-}$yield due to ion impact, known to be significant at this energy [15]. The beam profile is measured with a thin alumina $\left(\mathrm{Al}_{2} \mathrm{O}_{3}\right)$ scintillator viewed by an image-intensified CCD camera with an adjustable gate. A negatively biased cylinder $(-3 \mathrm{kV}<V<0)$ at the exit of the solenoid suppresses secondary electrons from ion impact on the scintillator. The light from the ion source causes a nonuniform background, which is subtracted using images captured in the absence of a beam pulse. The scintillator is $8 \mathrm{~cm}$ square.

The diagnostic station occupies the positions of the second and third solenoids in the NDCX-II accelerator, and is normally removed from the beam line.

\section{LITHIUM ION MEASUREMENTS}

The vacuum pressure is $\approx 2 \times 10^{-5}$ Torr when the emitter temperature is $1250^{\circ} \mathrm{C}$. Assuming the sum of the atomic cross sections for stripping, ionization, and charge exchange is $\sigma \approx 10^{-15} \mathrm{~cm}^{2}$, several percent of the ions in 
the beam interact with the background gas in the $90-\mathrm{cm}$ distance from the emitting surface to the beam diagnostics.

\section{A. Neutral atom emission}

In a separate test stand, small samples (2-3 mm diameter) of lithium aluminosilicate were used in source lifetime measurements using a DC extraction voltage of $\sim 0.1 \mathrm{kV}$ across a 4-mm gap. By comparing the lifetime of emitters operated continuously to the lifetime of emitters for which the extraction voltage was applied intermittently (3\%, $33 \%$, and $100 \%$ duty cycle), the ratio of the ion emission rate $\left(\nu_{i}\right)$ to the neutral emission rate $\left(\nu_{o}\right)$ was found to be of order unity. This is in sharp contrast to $\mathrm{K}^{+}$and $\mathrm{Cs}^{+} \mathrm{Al}-\mathrm{Si}$ emitters which yield a high current $\left(>10 \mathrm{~mA} / \mathrm{cm}^{2}\right)$ at 1025-1100 $\mathrm{C}$ and for which $\nu_{i} / \nu_{o} \gg 1$ [16]. The neutral emission rate is expected to increase with temperature, but the magnitude of the neutral rate here is not understood in detail. Nevertheless, the experimental results point to a possible method for extending the lifetime of the lithium sources through a rapid reduction of the emitter temperature by a few hundred degrees between beam extraction pulses so that $\nu_{o}$ is temporarily but significantly decreased. Though the heat capacity of the 10.9-cm diameter NDCXII emitter and substrate limits the frequency for temperature cycling, it should be advantageous during ion extraction interruptions of several minutes or more. Another technique we are exploring is operating the substrate at a lower temperature and quickly heating only the surface via an intense laser pulse to a temperature where the ion emission is satisfactorily high [17].

\section{B. Beam current and current density profiles}

The beam measurements reported here are for the first $10.9-\mathrm{cm}$ ion source installed in the new NDCX-II injector. The ion source has not depleted after $\approx 35$ hours of operation at $T>1200 \mathrm{C}$.

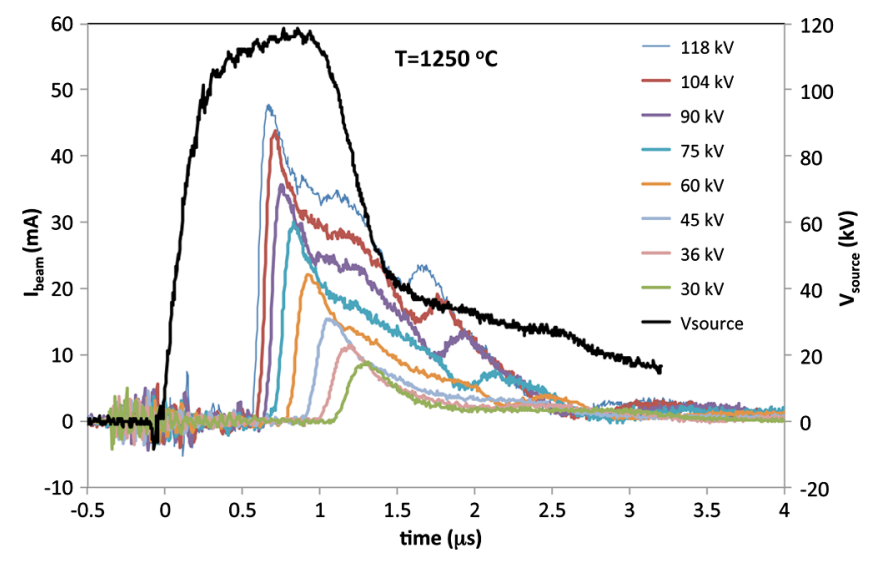

FIG. 5. Beam current measured in the Faraday cup for various injector voltages. The plotted voltage waveform is for a peak source voltage of $118 \mathrm{kV}$. The HV waveforms scale linearly with amplitude.

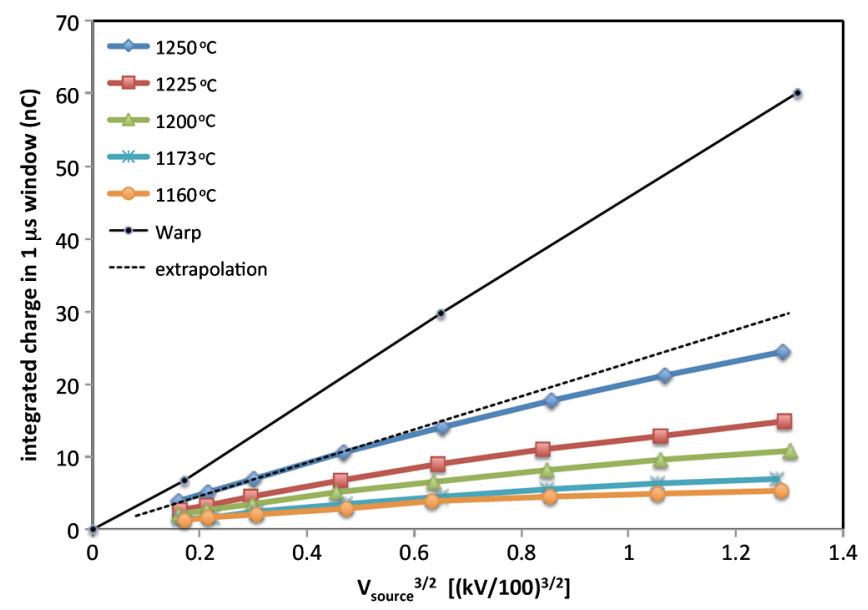

FIG. 6. Extracted beam current, integrated over $\approx 1 \mu \mathrm{sec}$ duration near the beginning of the current waveform vs injector voltage, for several source temperatures.

The beam current (Fig. 5) was measured in the Faraday cup, with a collector bias of $+2 \mathrm{kV}$ and a suppressor ring bias of $-2 \mathrm{kV}$.

These bias voltages effectively suppress the flow of secondary electrons from ion impact on the collector. The measurements show a contribution of contaminant ions arriving 1.5-2 $\mu \mathrm{sec}$ after the $\mathrm{Li}^{+}$ions. The contaminant species is most likely $\mathrm{K}^{+}$, according to the time of arrival at the Faraday cup, and consistent with the observations of others. Feeney et al. [18] reported $\mathrm{K}^{+}$contamination of $\mathrm{a} \mathrm{Li}^{+}$ion source, with the $\mathrm{K}^{+}$emission decreasing tenfold within the first $\sim 10$ hours of source

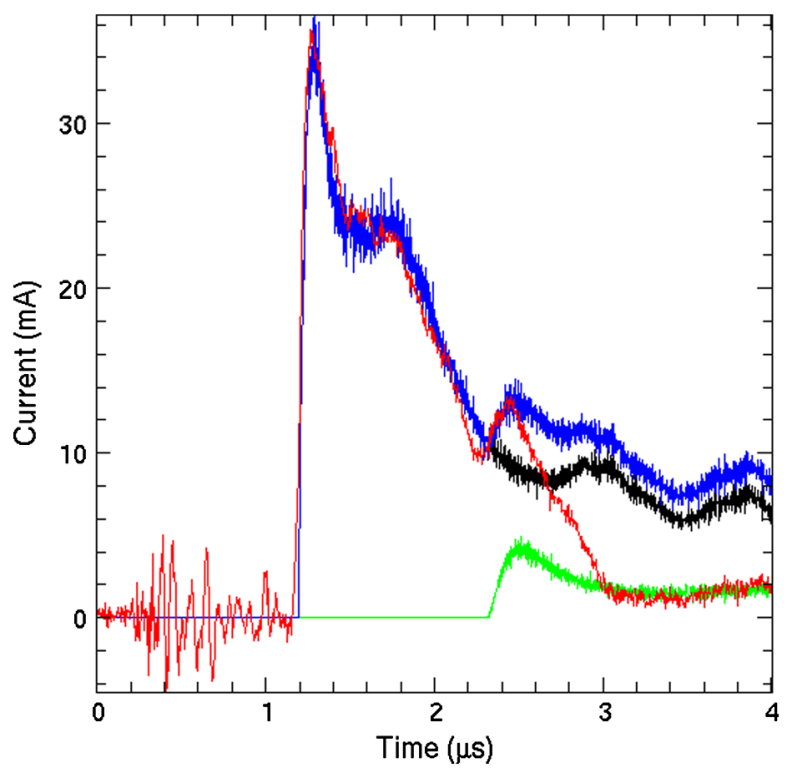

FIG. 7. WARP simulation of the beam current (blue) with the empirically adjusted model described in the text is compared to the experiment (red, $V_{s}=90 \mathrm{kV}, T=1250^{\circ} \mathrm{C}$ ). The model includes contributions from $\mathrm{Li}^{+}$(black) and $\mathrm{K}^{+}$(green). 

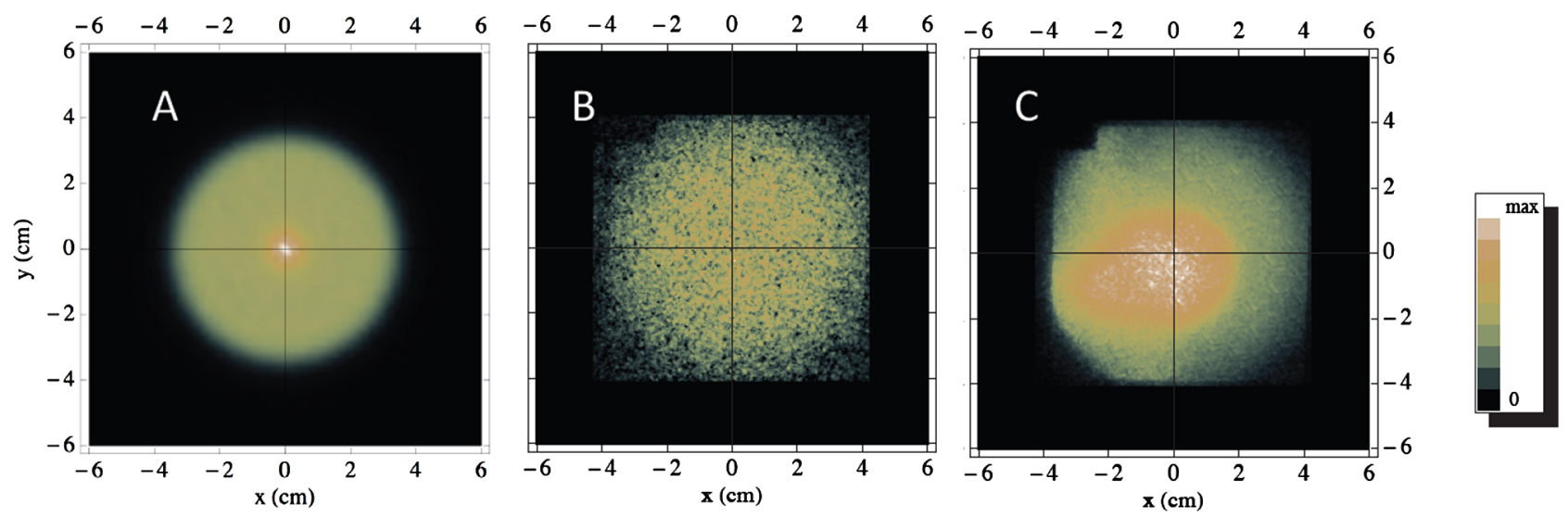

FIG. 8. (a) WARP simulations of the beam distribution at the scintillator plane, at $z=90 \mathrm{~cm}$. (b) Beam profile measured with the alumina scintillator and image-intensified CCD camera for $V_{s}=30 \mathrm{kV}$, gated for a $0.5 \mu$ sec window $\approx 0.2 \mu$ sec after the arrival of the beginning of the beam pulse. (c) Same as (b) except $V_{s}=119 \mathrm{kV}$.

operation, and Tan et al. [19] observed $\mathrm{K}^{+}$emission from a rubidium aluminosilicate source at the $1 \%-2 \%$ level. We have observed the $\mathrm{K}^{+}$current about $10 \%$ of the $\mathrm{Li}^{+}$after 20-25 hours of operation. In this case the $\mathrm{K}^{+}$perveance is approximately $24 \%$ of the $\mathrm{Li}^{+}$perveance. The source of the $\mathrm{K}^{+}$contamination in the beam is not known.

In the nonrelativistic limit, the ion gun perveance is

$$
P=\left(\frac{2 q}{m}\right)^{1 / 2} \frac{\lambda}{V_{\text {beam }}},
$$

where $\lambda=I / v$ is the line charge density, and $V_{\text {beam }}$ is the ion beam voltage. For space-charge limited extraction, the expected relationship is $I=P V^{3 / 2}$.

$I_{b}\left(V_{\text {inj }}\right)$ was measured for several operating temperatures and is shown in Fig. 6. To reduce the contribution of the initial peak in the current waveform from the analysis and interpretation, we have chosen to integrate the current waveform in a $1-\mu \mathrm{s}$ window that starts slightly before the initial rise of the current pulse. In this case, $V_{\text {accel }}=$ 0 , and the expected relationship from the Child-Langmuir theory of space-charge limited flow is both $I_{b}\left(V_{\text {inj }}\right)$ and the integrated charge $Q_{b}\left(V_{\text {inj }}\right)$ are proportional to $V_{\text {inj }}{ }^{3 / 2}$.

It is clear that the ion source is emission limited for all values of $V_{\text {inj }}$ measured, most notably at higher source voltage. The WARP space-charge limited prediction overestimates the measured current by about a factor of 2 . The $\mathrm{Li}^{+}$ion current is observed to increase at a given voltage and operating temperature by $\sim 20 \%$ over the course of several hours of running. The $\mathrm{K}^{+}$fraction did not change appreciably over this time.

In an effort to understand the Faraday cup data, WARP simulations with empirically adjusted contamination levels are in fair agreement with the measurements at $T=$ $1250^{\circ} \mathrm{C}$ and $V_{\mathrm{s}}=90 \mathrm{kV}$ (see Fig. 7). Parameters resembling the effective work function in an empirical model were fitted to the measurement. The emission was limited at the emitter, with a 5:95 ratio of $\mathrm{K}^{+}: \mathrm{Li}^{+}$. The model resembles the theory of Langmuir and Taylor [20] and the overall emission was also adjusted to match the measurements. These empirical parameters, however, do not match the Faraday cup data at other temperature and source voltage settings. The relative admixture of $\mathrm{K}^{+}: \mathrm{Li}^{+}$is expected to be temperature dependent, and also time dependent, due to the evolving reservoir of $\mathrm{Li}^{+}$in the aluminosilicate and the $\mathrm{K}^{+}$contaminant in the system.

Measured beam profiles are shown in Fig. 8, for two extraction voltages and are compared to WARP particle-incell simulations of the experiment. The experimental result at lower $V_{s}$, where the extraction is likely closer to the space-charge limit, is more symmetric than at higher $V_{s}$. The expected beam distribution, predicted by the WARP particle-in-cell code, is nearly uniform with an enhancement at the center of the particle distribution. The central enhancement is due to translaminar trajectories originating near the edge of the emitter. The rms beam radius, $r$, is 28 and $27 \mathrm{~mm}$ at $V_{s}=31$ and $120 \mathrm{kV}$, respectively. The WARP result has $r=25 \mathrm{~mm}$.

\section{CONCLUSIONS}

We have built and commissioned an intense lithium ion source and injector as the front end to an induction linear accelerator for warm dense matter and high energy density physics research. The injector operates in a pulsed mode, up to a maximum operating voltage of $130 \mathrm{kV}$, with a pulse duration of $\sim 1 \mu \mathrm{s}$ FWHM. The extraction of the beam is controlled with the voltage settings of two intermediate electrodes, determined by particle-in-cell modeling of the ion extraction.

A thin lithium aluminosilicate source coated on a porous tungsten substrate was chosen because of the demonstrated ability of aluminosilicates to produce high brightness beams of alkali ions at a high repetition rate. Lithium is 
most challenging among the alkalis due to the higher ionization potential. Earlier experiments with small area sources operated at $T=1275 \mathrm{C}$ showed a space-charge limited current density of $1 \mathrm{~mA} / \mathrm{cm}^{2}$ with no detected contamination from other ion species.

Based on these observations, the physics design of the NDCX-II injector called for a large $\left(93 \mathrm{~cm}^{2}\right)$ surface area emitter capable of producing $\sim 1 \mathrm{~mA} / \mathrm{cm}^{2} \mathrm{Li}^{+}$under space-charge limited extraction conditions. Managing the $\sim 4 \mathrm{~kW}$ of power to heat the source uniformly and maintaining an acceptable temperature of surrounding components was achieved through finite-element modeling of the heating and cooling system. Measurements of the filament heater power vs temperature of the blank emitter are in excellent agreement with the model. The design is modular, with a nearly freestanding filament within a cavity of the porous tungsten substrate, enabling relatively easy maintenance of the filament assembly and replacement of depleted emitters.

The first ion source produces a short peak current of $47 \mathrm{~mA}$, followed by a lower, $\approx 35 \mathrm{~mA}$ current for most of the rest of the pulse. $\mathrm{K}^{+}$forms a 5\%-10\% contaminant in the Faraday cup data, with a time-of-flight separation of $>1 \mu$ s between the species, depending on voltage. The waveform contribution from $\mathrm{K}^{+}$can be reproduced by a particle-in-cell model of the injector beam, with an empirically adjusted admixture and emission limit for $\mathrm{Li}^{+}$and $\mathrm{K}^{+}$.

The current density profile was imaged with a scintillator and CCD camera. At lower extraction voltage, it shows a smooth distribution with the highest intensity near the center of the beam, in qualitative agreement with the particle-in-cell model. The lifetime of this source is $>25$ hours, and the $\mathrm{Li}^{+}$emission is steadily increasing during this time. A current of $35 \mathrm{~mA}$ corresponds to an average current density of $0.4 \mathrm{~mA} / \mathrm{cm}^{2}$ at the emitter and we speculate that this may be due to limited coverage and emission over some fraction of the surface of the emitter.

Regarding the overall two times lower current beam than predicted by WARP simulations, our speculation is that it is plausibly due to an uneven emission limit over the area of the emitter. This is supported by the asymmetric current density distribution at high extraction voltage [Fig. 8(c)], while at lower voltage the beam is more symmetric [Fig. 8(b)]. At the lower voltage the emission limit is apparently closer to, but not quite matching, the calculated space-charge limit.

Spalling of fragments of aluminosilicate was observed during the cooling cycle after melting onto the substrate. We are refining the coating and melting procedures to achieve a more uniform coating and higher emission current to match our results with the smaller emitters.

Using this first beam from the injector, commissioning of the NDCX-II induction accelerator is underway. The beam is satisfactory for testing the acceleration modules, beam diagnostics, and the final focusing and target diagnostics.

\section{ACKNOWLEDGMENTS}

This work was supported by the U.S. Department of Energy under Contract No. DE-AC02-05CH1123.

[1] L. R. Grisham, Phys. Plasmas 11, 5727 (2004).

[2] A. Friedman et al., Phys. Plasmas 17, 056704 (2010).

[3] J. J. Moschella, B. R. Kusse, J. P. Longfellow, and J.C. Olson, J. Appl. Phys. 70, 3418 (1991).

[4] T. J. Renk, G. C. Tisone, R. G. Adams, D. J. Johnson, C. L. Ruiz, and G. W. Cooper, Phys. Plasmas 6, 3697 (1999).

[5] H.L. Daley and J. Perel, Rev. Sci. Instrum. 42, 1324 (1971); I. Katsumata, M. Yamasaki, K. Murakami, M. Fujimoto, H. Tsukahara, Y. Nanjo, and H. Yoshimura, Rev. Sci. Instrum. 65, 1392 (1994).

[6] L. R. Prost, P. A. Seidl, F. M. Bieniosek, C. M. Celata, A. Faltens, D. Baca, E. Henestroza, J. W. Kwan, M. Leitner, W. L. Waldron, R. Cohen, A. Friedman, D. Grote, S. M. Lund, A. W. Molvik, and E. Morse, Phys. Rev. ST Accel. Beams 8, 020101 (2005); D. Baca, J. W. Kwan, and J. K. $\mathrm{Wu}$, in Proceedings of the 20th Particle Accelerator Conference, Portland, OR, 2003 (IEEE, New York, 2003), p. 3294.

[7] D. M. Thomas, W. P. West, and K. McCormick, Rev. Sci. Instrum. 59, 1735 (1988).

[8] Atshushi Kojima, Kensaku Kamiya, Harukazu Iguchi, Takaaki Fujita, Hideto Kakiuchi, and Yutaka Kamada, Rev. Sci. Instrum. 79, 093502 (2008).

[9] Prabir K. Roy, Wayne G. Greenway, Joe W. Kwan, Peter A. Seidl, William L. Waldron, and James K. Wu, Rev. Sci. Instrum. 82, 013304 (2011).

[10] J. H. Takakuwa, J. Y. Jung, G. T. Kehl, J. W. Kwan, M. Leitner, P. A. Seidl, W. L. Waldron, D. Grote, B. Sharp, and A. Friedman, in Proceedings of the 2011 Particle Accelerator Conference, NY, USA (IEEE, New York, 2011), WEP293 [http://accelconf.web.cern.ch/AccelConf/ PAC2011/papers/wep293.pdf].

[11] M. Rodriguez Ripoll, "Drawn Tungsten Wires for Lighting Applications" SciTopics. Retrieved 2012, from http://www.scitopics.com/Drawn_Tungsten_Wires_ for_Lighting_Applications.html.

[12] ANSYS, Inc., http://www.ansys.com/.

[13] A. V. Pustogarov, G. N. Mel'nikov, A. N. Kolesnichenko, V.D. Daragan, and D.D. Chepiga, Thermophysical Properties Of Porous Tungsten At Temperatures of 12003200 OK (Plenum Publishing Corporation, New York, 1975); translated from Poroshkovaya Metallurgiya, 11, 52 (1974).

[14] D. P. Grote, A. Friedman, I. Haber, W. Fawley, and J.-L. Vay, Nucl. Instrum. Methods Phys. Res., Sect. A 415, 428 (1998).

[15] Arthur W. Molvik, Michel Kireeff Covo, Frank M. Bieniosek, Lionel Prost, Peter A. Seidl, David Baca, Adam Coorey, and Akira Sakumi, Phys. Rev. ST Accel. Beams 7, 093202 (2004). 
[16] E. Chacon-Golcher, Ph.D. thesis, University of California, Berkeley, 2002; E. Chacon-Golcher, D. Baca, and J. W. Kwan, Rev. Sci. Instrum. 73, 1036 (2002).

[17] P. A. Ni, J. W. Kwan, P. K. Roy, and W. L. Waldron, Rev. Sci. Instrum. 82, 023304 (2011).
[18] R. K. Feeney, William E. Sayle, and J. W. Hooper, Rev. Sci. Instrum. 47, 964 (1976).

[19] T. L. Tan, P. P. Ong, T. M. Fong, and K. A. Soo, Int. J. Mass Spectrom. Ion Process. 134, 221 (1994).

[20] J. B. Taylor and I. Langmuir, Phys. Rev. 44, 423 (1933). 